\title{
CUERPO Y PALABRA
}

\author{
Teresa Houghton $P$. \\ Universidad Santo Tomás
}

Recibido: marzo 9 de 2005

Aprobado: mayo 6 de 2005

\section{Resumen}

En la introducción del artículo se ubica el tema del cuerpo y la palabra en el horizonte del seminario Corporeidad humana en Santo Tomás ${ }^{1}$ y se presenta la metodología: seguimiento de los textos tomistas y aplicación de estos a la vida cotidiana. En las secciones siguientes se analiza el signo en su relación con la corporalidad humana y las clases de signos (parte I), la palabra como signo o cuerpo del pensamiento, y, como tal, compleja, múltiple, histórica y referida a la realidad (parte II), las funciones que tiene la palabra de expresar, informar y representar (parte III), y a manera de conclusión, una propuesta de aplicación en la pedagogía.

\section{Palabras clave}

Santo Tomás, signo, semiosis, palabra

\section{Abstract}

The introduction of the article puts the theme of body and word in the habeas of the seminar Human Corporiety in Saint Thomas, as the result of the research accomplished by the SITA group (Sociedad internacional Tomás de Aquino) of Bogotá. It presents the methodology: to follow the texts of Saint Thomas and their applicability to daily life. In the next sections signs and their kinds are analyzed in relation with the human body (I); the word as sign or as body of thought, as complex, manifold, historic and refered to reality (II); the uses of the word: to express, to inform, to state (III), and as a way of conclusion, a proposal of its application in pedagogy.

\section{Key words}

Saint Thomas, sign, semiosis, word

\footnotetext{
Seminario que es fruto del trabajo investigativo del Grupo de SITA (Sociedad Internacional Tomás de Aquino) de Bogotá, que se proyecta a estudiantes universitarios, desde el I semestre de 2004.
} 
Hoy podemos responder al "¿por qué filosofar?" con una nueva pregunta: “¿por qué hablar?”. $Y$, puesto que hablamos, ¿qué es lo que hablar quiere decir y no puede decir?

Jean Francois Lyotard, ¿Por qué filosofar?

El presente artículo no corresponde a un estudio de especialista en el pensamiento de Tomás de Aquino, ni en el sentido propio del término, ni en el sentido de Bernard Shaw, quien escribe que un especialista es alguien que "sabe cada vez más de menos", porque "nadie puede ser un especialista puro sin ser un idiota en el sentido estricto de la palabra" ${ }^{2}$. Son estas las reflexiones de una estudiante del tomismo, así que empezaré citando esa bella oración de Tomás de Aquino para antes del estudio, que pide "acierto al empezar, dirección al progresar y perfección al acabar".

El tema supone la ubicación del tema del cuerpo en los dualismos antiguos y nuevos; la esencia de la corporeidad o del cuerpo humano desde el rigor de las categorías de la lógica y de la metafísica; el proceso de construcción del concepto que nos lleva hasta las puertas del verbo mental; etc. Aquí se pretender dejar hablar a la palabra... Somos el único animal capaz de hablar de su acto de hablar.

El esquema que se sigue en estas reflexiones tiene tres momentos:

1. El hombre necesitado de signos y, por ello, de lenguaje, no obstante su corporeidad

2. La palabra como signo-cuerpo del pensamiento, verbo mental
3. La funciones de la palabra.

Las fuentes primarias son algunas cuestiones de la Suma Teológica, especialmente la cuestión 60 de la parte III, en donde Santo Tomás habla de los signos a propósito de los sacramentos, la cuestión 85, artículo 3, y la cuestión 103, artículo 3, de la parte II de la IIa, donde se refiere a las imágenes; también la cuestión 107 de la parte I, donde habla del lenguaje de los ángeles, algunos apartes del Comentario al Perihermeneias de Aristóteles y algunos artículos de la Cuestión Disputada De Veritate, especialmente el 4, el 9 y el 12 .

Como fuentes secundarias, una lección de ese sabio dominico a quien se le debe justamente que nos hayamos preocupado del hablar latinoamericano, el padre Joaquín Zabalza Iriarte, en El derecho, Tomás de Aquino y Latinoamérica ${ }^{3}$, y las lecciones de otro maestro, el doctor Alberto Cárdenas Patiño, especialmente en su discurso para ingresar a la Sociedad Colombiana de Filosofía "Aproximación a la semiótica tomista”.

\section{El hombre necesitado de signos}

Paradójicamente, el hombre, aunque a través de su cuerpo se acerca a lo otro de la realidad, también por estar en-carnado necesita una mediación para trascender lo que no le es accesible directamente. Por ello, nece-

2 George Bernard Shaw, Ironías y verdades (Buenos Aires: Longseller, 2001) 79.

3 Joaquín Zabalza Iriarte, El derecho, Tomás de Aquino y Latinoamérica (Bogotá: Ed. USTA, 1982). 
sitamos signos que nos acerquen a lo inescrutable, el pensamiento, por ejemplo, el querer interior, nuestras voliciones y afectos.

El signo tiene como función acercarnos lo incognoscible y a la vez arrojarnos a ello. El signo tiene una esencia, re-presenta un significado.

Los signos, dice Santo Tomás, "son connaturales al hombre, porque es propio del hombre llegar a lo desconocido a través de las cosas conocidas" ". Si bien él no escribió un tratado especial sobre el tema, su filosofía del lenguaje está muy relacionada con la teoría de los signos y el lenguaje articulado y verbal.

Los signos son en principio de dos clases:

- Signo formal, cuando el objeto representado se conoce en él y simultáneamente con él, porque tiene la misma esencia del objeto, sólo que con distinta existencia. El signo formal por excelencia es el concepto. Conviene recordar que el concepto tiene una existencia mental, mientras que la cosa, el objeto, la tiene real. Así que, por ejemplo, al conocer un paisaje, yo lo conozco en el concepto de paisaje y simultáneamente con él. Sólo que el concepto existe en la mente y el paisaje fuera de ella.

- Signo instrumental, cuando el objeto es re-presentado por una esencia distinta de él, de manera que conocemos primero el signo y éste nos remite a la esencia de lo representado por él. El signo “+” de la suma debe ser leído primero por noso- tros, por el alfabetizado, y sólo después nos remite a la operación de la adición. Así, la cadena de significantes y significados puede hacerse interminable. Es lo que el profesor Cárdenas llama 'semiosis' o proceso de relevo intersígnico. Por eso los seres humanos vamos de señal en señal, avanzando entre luces y sombras, en un interminable sendero de interpretaciones. Pensar..., filosofar, no se trata tanto de pasar de las sombras a la luz sino de ser capaz de orientarse en medio de la penumbra.

Este signo instrumental puede ser: a) natural, cuando su relación con lo representado es de causalidad o dependencia, como ocurre con el aroma de una rosa que nos lleva naturalmente a ella; b) convencional, cuando somos nosotros los que determinamos que esto represente aquello, así como la bandera representa un país.

Es aquí donde se sitúa la palabra. Signo convencional, porque, de no serlo, tendríamos todos el mismo idioma ${ }^{5}$. En muchos textos Santo Tomás da relevancia al valor de los signos y a su referencia al hombre como ser corpóreo, necesitado de dar y recibir significados. El ser propio del signo es remitir más allá de sí mismo, con-vocar la trascendencia de señales, gestos, palabras, grafías, íconos, etc. Tiene por función hacer ir más allá, es in-tencional ${ }^{6}$. Así lo dice cuando habla de las imágenes religiosas: "Nuestra devoción, por consiguiente, a una imagen, en cuanto imagen, no termina en ella sino que va dirigida a lo que ella representa"7. Y cuando distingue dulía (culto a los santos) de

\footnotetext{
Santo Tomás de Aquino, Suma Teológica, Vol. I (Madrid: B.A.C., 2001) III, q.60, a.2 , c.

5 Cf. Mauricio Beuchot, O.P., "Filosofía del lenguaje”, Introducción a la filosofía de Tomás de Aquino (México: UNAM, 1992) 41.

6 Cf. Santo Tomás de Aquino, Cuestiones Disputadas De Veritate, trad. Jesús García López (Pamplona: U. de Navarra, 1967) Art. 9, 4.

7 Tomás de Aquino, Suma Teológica, II-II, q.85, a.3 ad 3.
} 
latría (culto a Dios): “El movimiento hacia la imagen en cuanto imagen se refiere a lo que la imagen representa"8 . "El lenguaje exterior por medio de la voz es necesario debido al obstáculo del cuerpo"9.

Así que somos seres corpóreos, dotados de sentidos, capaces de llegar a las cosas, pero necesitamos signos para acercarnos a las esencias, para trascender esas cosas. Porque nuestra interioridad es inescrutable. Necesitamos el signo formal, el concepto, para entender el mundo y lo que nos decimos; y el signo instrumental, convencional, la voz, el gesto, la palabra, para expresar lo entendido, y la escritura, palabra escrita, para entregarlo a otros más allá del espacio y del tiempo. Comentando el Perihermeneias de Aristóteles, dice Santo Tomás:

Y si efectivamente el hombre fuese naturalmente un animal solitario, le bastarían las pasiones del alma, con las que se acomoda a las cosas, para tener en sí un conocimiento de ellas; pero como el hombre es por naturaleza un animal político y social, es necesario que los conocimientos de un hombre se manifestasen a otros, lo que se hace por la voz; y por ello fue necesario que hubiese voces significativas, en orden a que los hombres conviviesen entre sí (...).

Además, si el hombre usara sólo el conocimiento sensitivo, que atiende sólo al aquí y al ahora, le bastaría para convivir con otros la voz significativa, igual como a los restantes anima- les (...) pero porque el hombre hace uso también del conocimiento intelectual, que abstrae del aquí y del ahora, le sigue la preocupación no sólo de lo presente según el lugar y el tiempo, sino también de lo que está distante en cuanto al lugar y es futuro respecto del tiempo; de donde, a fin de que el hombre también hiciese manifiestos sus conocimientos a quienes están distantes en cuanto al lugar y a quienes están por venir en un tiempo futuro, fue necesario el uso de la escritura $^{10}$.

La u-cronía y la u-topía requieren de nuestras palabras. Las necesitamos para ir más allá del tiempo y más allá del espacio en nuestro ser con otros.

De manera que la voz, los gemidos, los gritos, la risa son lenguajes naturales. Los códigos, las palabras, la escritura, son convencionales. Ambos son necesarios, sobre todo porque no estamos solos. "Del hablar en sí mismo no podemos prescindir, porque (...) nos perderemos como seres hablantes, y para unos seres hablantes, el perderse como tales, es perderse como seres"11.

Por las palabras entregamos las cosas como las pensamos y las vivimos... los conceptos y los afectos, es decir, las pasiones. En este mismo Comentario, Santo Tomás aclara que se entiende por "pasiones del alma” afecciones del apetito sensible, y aquí éstas significan sobre todo el término de esas afecciones, es decir, las concepciones del intelecto.

\footnotetext{
Tomás de Aquino, Suma Teológica, II-II, q. 103, a.3 ad. 3.

Tomás de Aquino, Suma Teológica, I, q. 107, a.1 ad 2.

10 Santo Tomás de Aquino, Comentario al libro de Aristóteles sobre la interpretación (In Perihermeneias) (Pamplona: EUNSA-U. de Navarra, 1999) I,2 (16 a 3).

11 Abelardo Lobato, O.P., El hombre en cuerpo y alma, Vol. I de El pensamiento de Tomás de Aquino para el hombre de hoy (Valencia: EDICEP, 1994) 509.
} 


\section{La palabra, signo-cuerpo del pensamiento o verbo mental}

Cuando se explica la ideogenésis en el pensamiento tomista, queda claro que el proceso de conocimiento se inicia cuando la realidad irrumpe en nosotros por la experiencia y suscita la cadena de sensaciones e imágenes recogidas por el sentido común, que a manera del arco iris discrimina colores, olores, sabores, etc., y los recompone hacia la formación de las especies, hasta que se llega al concepto, el mas perfecto signo que permite conocer en él y simultáneamente con él, lo real. "Por cuanto al volverse la mente a considerar en acto lo que posee en hábito, se habla uno a sí mismo; pues el mismo concepto mental se llama realmente palabra interior (...) hablar a otro no es más que manifestarle algún concepto de la mente" ${ }^{12}$. Si seguimos ese movimiento o semiosis desde el verbo mental o concepto al verbo exterior, llegamos a la palabra.

\subsection{Palabra, cuerpo del pensamiento}

La palabra reviste de corporalidad al verbo interior. Si pensar es hablarnos a nosotros mismos, ese pensamiento toma cuerpo por la palabra exterior, se hace voz, manos, ojos, se multiplica..., materializa el pensamiento y el querer internos. Exhibe la patencia del ente. Es la verbalización de la verdad y la presencia objetiva del conocimiento.

Carne del verbo mental. Aunque signo convencional, lo mismo que el cuerpo está investida desde nuestro interior por lo pensado y lo vivido, y, como una extensión de nuestro cuerpo, nos permite llegar más allá de él, a la mente y al afecto de los demás. Ella rompe la barrera de lo corporal. El verbum cordis se traduce en verbum vocis. Santo Tomás lo expresa bellamente:

Se oculta el pensamiento del hombre a los demás por el espesor del cuerpo. Así vemos que aun cuando la voluntad decide manifestar a otros el concepto de la mente, no es conocido inmediatamente, sino que es necesario hacer uso de algún signo sensible. Dice sobre esto Gregorio en II Moral: "En el secreto interior de la mente estamos ocultos a las miradas extrañas, como tras el muro del cuerpo; pero cuando deseamos manifestarnos a nosotros mismos, parece que salimos, a través de la lengua, para mostrarnos tal como somos interiormente" ${ }^{13}$.

De modo que, como escribe el profesor Cárdenas, "el proceso sígnico no termina en el verbum mentis (...) el hombre naturalmente rompe a hablar, a decir palabras" ${ }^{14}$. Porque la palabra tiene un supuesto antropológico: la tendencia natural humana a la comunicación. No sólo la realidad está necesitada de su traducción en signos, sino que nuestra interioridad los precisa para comunicarse a otros. Santo Tomás lo explica muy bien en la primera parte de la Suma, q. 85, donde habla del modo y orden del conocimiento.

La relación entre los dos verbos está muy puntualmente explicada en De Veritate, especialmente en las cuestiones 9 , art. 4 , y 4 , art. 1, donde establece cómo uno se debe al otro: la palabra no sería nada sin la fecundidad que recibe del pensamiento:

2 Tomás de Aquino, Suma Teológica, q.107 C.

13 Tomás de Aquino, Suma Teológica, I, q.107, a.1 ad.1.

14 Alberto Cárdenas Patiño, “Aproximación a la semiótica tomista”, Introducción a la semiología (Bogotá: Ed. USTA, 1996) 57. 
Porque la palabra exterior es algo sensible, sucede que es mejor conocida para nosotros que la palabra interior. Por eso, el mismo vocablo 'palabra' lo utilizamos para designar a la palabra exterior. Sin embargo, la palabra interior es naturalmente más importante que la palabra exterior, pues esta existe por la palabra interior y dice referencia a ella ${ }^{15}$.

Igualmente explica su diferencia en la Cuestión Disputada De Potentia Dei, donde habla de la función de arbitrio que tenemos frente al lenguaje y, en consecuencia, la posibilidad de la mentira. "Lo verdadero se dice (...) del hombre que puede elegir palabras verdaderas o falsas, o que hace una estimación verdadera o falsa de sí o de los otros, mediante las cosas que dice o que hace $(\ldots))^{\prime 16}$.

Y al hablar en la parte II de la II de la Suma, sobre la verdad como parte de la justicia: "La manifestación de la verdad es acto de la voluntad" ${ }^{17}$.

Si bien Santo Tomás le da importancia grande a la palabra oral, como se puede constatar en el tratado de los sacramentos, es muy claro al señalar allí mismo que este no es el único signo que le permite llegar a lo desconocido, y que por ello el hombre combina múltiples lenguajes.

Así que, como dice el Padre Joaquín Zabalza -de quien tomo el esquema de lo que sigue en esta parte de la reflexión-, el hombre es animal hablador porque capta el interior de las cosas y, por esa relación entre racionali- dad y oralidad, porque es animal apalabrado, se puede decir que:

\section{a) La palabra es problema}

No sólo como mediación implica un reto a la comprensión, sino porque ella misma se hace tema o problema de la filosofía, de la ciencia del lenguaje, de los procesos de comunicación, de la pedagogía, como veremos más adelante. También porque con las palabras cuestionamos, disputamos, confrontamos, preguntamos. Ella abre perplejidades y puede también cerrar puertas. "Quien habla, renuncia a decirlo todo y acepta el riesgo de ser malentendido" ${ }^{18}$. Wittgenstein dice algo apropiado para este tema: "Debes aceptar los fallos de tu propio estilo como las fealdades de tu propio rostro" 19 .

\section{b) La palabra es múltiple}

No sólo es interior y exterior, como ya se dijo, sino múltiple, en cuanto entrega el interior de cada uno, con todas las marcas y variaciones del yo. Igual que los cuerpos que, aunque tienen todos estructuras iguales, una cabeza, dos ojos, dos pies, tiene cada uno el sello inconfundible de nuestra individualidad.

Como el ser, que se dice de muchas maneras, el ser de nuestros pensamientos y afectos se manifiesta de múltiples formas. Es esto lo que fundamenta la riqueza, pero también la problematicidad de nuestras relaciones. Decimos palabras que creemos llevan de modo transparente nuestras intenciones, y que, al entregarse a otros, pueden ser entendidas de muchas maneras. Por esa textura o tesitura del hablar, hay palabras de alta o baja

\footnotetext{
Tomás de Aquino, Cuestiones ..., 4, a.1, c.

Tomás de Aquino, Cuestiones ..., c 1, a.3, c.

Tomás de Aquino, Suma Teológica, II-II, q.109, a.3 ad 2.

Daniel Innerarity, “La filosofía como una de las bellas artes” (Barcelona: Ariel Filosofía, 1995$) 74$.

Ludwig Wittgenstein, citado de Obras completas, 8, 557 c., en Innerarity, “La filosofía ...”, 76.
} 
moral..., alegres o melancólicas..., sobrias o barrocas..., precisas y certeras, o de amplios rodeos y vistazos generales..., de piel para adentro o de labios para afuera..., polémicas y cautas $^{20}$. Esta es la riqueza y también la precariedad de la multiplicidad, de la plurisemia. Por ellas podemos decir más de lo que pensamos, pero también, menos. Aunque disculparnos por no podernos expresar bien, puede ser una manera de esconder nuestra incapacidad para el concepto. Sólo una pequeña porción del discurso humano puede reclamar la veracidad escueta o el puro contenido informativo. Así como sólo una parte de nuestro cuerpo deja ver el misterio de lo que somos.... Así como el vestido manifiesta la indigencia de nuestra desnudez, la palabra indica la finitud de nuestra manera de hacernos cargo de la realidad. Por eso realmente nunca hablamos en general, y también por eso todo hablar "se queda corto" frente a lo que queremos decir.

\section{c) La palabra referida pero distinta de la realidad}

Ni es la pura realidad, ni sólo mediación. Como hemos repetido, la realidad primero se hace verbo mental y sólo después, palabra que se reviste del carácter, de la fuerza o la vacilación del momento en que se dice, $\mathrm{y}$ del tono que le da la acogida de quien la recibe. Así que nunca se identifican. Por eso la idea de la "verdad desnuda” es una metáfora con una larga historia, iniciada paradójicamente por un gran retórico del siglo IV, Lactancio, quien en el libro 3 de Divinae Institutiones habla de una verdad desnuda querida por Dios, que el ornamento retórico no hace mas que maquillar, mientras que la verdad simplex et nuda es suficientemente elocuente “quia satis ornata per se est” (III,
1, 3) $)^{21}$. Y Bacon, en el primer ensayo dice: "La verdad es una luz diurna desnuda y abierta que no muestra las máscaras y los disfraces y las pompas del mundo sólo a medias, embaucadora y exquisitamente, como los candelabros"22. No llegamos a la verdad desnudando nada, sino vistiendo adecuadamente el pensamiento.

\section{d) La palabra tiene historia}

Desde su origen, la vida de las palabras o su uso les va dando una impronta. Como ocurre con los cuerpos, donde va quedando inexorable pero también gratamente nuestra propia historia (por eso no hay que renegar de las arrugas o de las canas). Ese sentido tienen las etimologías, y por eso es preciso hacer también la etimología de nuestra propia realidad. En los lenguajes encontramos los mundos pensados y vividos de las gentes. Por eso, la cercanía o la brecha de las generaciones se percibe primero en el lenguaje. Por eso, un "adulto civilizado, normal y de buenas costumbres” (decía un manual de urbanidad) tiene dificultad para entrar en el mundo donde las niñas se dicen cotidianamente entre sí “oiga, marica”, y los muchachos “oiga, güevón”, donde la profesora es "la cucha intensa”, la rumba es "una chimba”, o la falta de plata es "estar en la inmunda”. Como nuestro cuerpo, las palabras son acceso a la realidad y puerta de entrada a nuestro interior.

\section{Funciones del lenguaje}

Llegados a este punto, casi sobra explicitar para qué el lenguaje, para qué las palabras. Igual que no tenemos mucha necesidad de explicar para qué el cuerpo.

\footnotetext{
Cf. Innerarity, “La filosofía ...”, 77.

Lactancio, Divinae Institutiones, citado en Innerarity, "La filosofía ...”, 69.

22 Francis Bacon, The Works of Francis Bacon, Vol. VI (Stuttgart: Frommann, 1963) 377.
} 


\section{a) Es el fundamento de la comunicación}

Lo vimos en el comentario al Perihermeneias, y entre muchas, una cita más: "Hay dos clases de lenguaje: el interior, por el que habla uno consigo mismo; y el exterior, por el que habla con otro" 23 .

b) En esa comunicación cumple al menos tres funciones:

El lingüista R. Jacobson y otros las diferencian según los factores de la comunicación. Señalo solamente lo que me parece más relevante teniendo en cuenta lo dicho anteriormente.

i) Función expresiva o manifestativa. Es común con los animales y se da en el nivel coloquial, donde la palabra, como dice el profesor Cárdenas, ex-presa, libera el pensamiento y la vivencia de múltiples maneras, como ya lo dijimos. Santo Tomás lo señala retomando a San Agustín: "Dice San Agustín en II De Doct. Christ. que el primado de significación entre los hombres lo tienen las palabras, ya que éstas se pueden combinar de diversas maneras para significar diversos conceptos de la mente, por lo que las palabras son el mejor medio para expresar con precisión nuestras ideas”24.

De hecho, cuando hablamos, comunicamos marcos afectivos particulares, seleccionamos y omitimos, hablamos de lo que podría ser. "Hablar es refutar lo inexorablemente empírico del mundo”25.
Esto ocurre también cuando callamos: "Sin insinuaciones o silencios sería muy difícil expresar ese mundo de enredos en el que vivimos y por cuya simplificación siempre pagamos un precio demasiado elevado”26.

A propósito del silencio, se han dado muchas interpretaciones al canto XII de la Odisea en el que Ulises, atado al mástil, escucha las voces de las sirenas. Una de ellas, la de Kafka, llama la atención: insinúa que las sirenas sólo simulaban cantar porque sabían que al hombre no se le puede vencer con palabras sino con el silencio. Es posible que alguien se hubiera salvado de su canto, pero nadie puede vencer su silencio. El poder de la palabra o del mito está en el silencio... ${ }^{27}$.

ii) Función informativa. Se da en el nivel técnico o instrumental, donde se fijan los saberes y donde la palabra actúa sobre otros. Cumple un papel de convocatoria. En este nivel deberíamos escuchar las voces de los silenciados, de los marginados de los necesitados... y un largo etcétera. También en este nivel se mantiene la comunicación o se fija, por ejemplo, la tradición (en el sentido de tradere: llevar; no en el de trahere: traicionar). Para Santo Tomás, la palabra oral o escrita es la vía de acceso a las $\operatorname{cosas}^{28}$.

iii) Función re-presentativa o referencial. Esto, en el nivel científico. Porque representa o simboliza, remite a la realidad, no sólo la del mundo objetivo sino también la del mundo interior subjetivo.

\footnotetext{
3 Tomás de Aquino, Suma Teológica, I, q.107, 1,2.

Tomás de Aquino, Suma Teológica, III, C.60, a.6, c.

Innerarity, “La filosofía ...”, 72-73.

Innerarity, "La filosofía ...”, 72-73.

Orlando Mejía, De clones, ciborgs y sirenas, Colección Artes y Humanidades (Manizales: Ed. Universidad de Caldas, 2001) 28.

28 Cf. Tomás de Aquino, Cuestiones ..., Q.12, a.7, ad 5.
} 
Esta función es privativa nuestra; por eso Cassirer habla del hombre como animal simbólico.

Por el compromiso de realidad que tiene la palabra, es preciso someter lo que decimos a la crítica, igual que ponemos la cara, sometemos el rostro, el cuerpo, a la mirada de otros, como lo señala Santo Tomás en el Comentario a las Sentencias de Pedro Lombardo. El estilo es la presencia de cada uno en sus palabras y es la condición de posibilidad de entendidos y malos entendidos. Cuando hablamos, las palabras ruedan por un campo ajeno, más allá de nuestro cuerpo, sin que podamos recuperarlas. No sabemos qué harán los demás con lo que hemos dicho. Sartre lo decía de manera muy fuerte: "Las palabras viven de la muerte de los hombres, se unen a través de ellos; cada frase que formo, su sentido se me escapa, me es robado; cada día y cada hablante altera para todos las significaciones, los otros vienen a cambiármelas hasta mi boca”29.

Y Humboldt: "Nadie piensa con la palabra exactamente lo mismo que el otro, y la mas pequeña diferencia continúa temblando en el lenguaje, como el círculo en el agua. De ahí que toda comprensión sea siempre al mismo tiempo una no-comprensión, toda consonancia en pensamientos y sentimientos también una disonancia”30.

En las funciones expresiva y referencial se fundamenta la teoría de la estética como parte de la semiótica.

No quisiera dejar de hacer una corta reflexión sobre la palabra como instrumento de la pedagogía, porque la herramienta del maestro es sobre todo la palabra.
Cuando algo se lee, se estudia o se contempla, siempre esto se hace en cuanto expresión de un verbo interno. Porque la palabra que enseña es un puente entre el concepto y la comprensión del otro. De ahí la necesidad, para el maestro, para el periodista, el psicólogo, el abogado... en fin, para todos los que trabajamos primordialmente con la palabra, de usar el lenguaje con corrección, oportunidad y adecuación. Los dos mejores descubrimientos del discurso humano son la brevedad y la elegancia. Y Nietzche decía que mejorar el estilo es mejorar el pensamiento.

Dice Santo Tomás que "hablar es ordenar el concepto intelectual a otro, de modo que le sea inteligible según la intención del que habla"31. Por eso tal vez la oración de Santo Tomás para antes del estudio, pide primero:

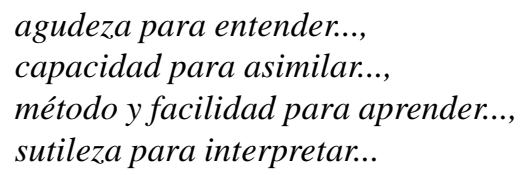

y sólo después: “gracia copiosa para hablar”.

En su filosofía de la educación, Santo Tomás insiste mucho en la necesidad de extender las palabras con los ejemplos y otras señales, siempre en cuanto eso, señales que lleven más allá de sí mismas, hasta que por sobriedad y ascesis mental se vuelvan innecesarias en cuanto sensibles.

El maestro ha de decir lo que conviene cuando conviene; es la misma mesura que hemos de tener con la presencia corporal: el cuerpo es presencia que habla, pero también se puede hablar con la ausencia. Hay que saber hacer "mutis por la puerta del foro".

\footnotetext{
J. P. Sartre, Crítica de la razón dialéctica, citado en Innerarity, "La filosofía ...” 211.

30 W. V. Humboldt, Obras completas, citado en Innerarity, "La filosofía ..." 88.

31 Tomás de Aquino, Suma Teológica, I, q. 107, a. 1, c.
} 
Hasta el tono de voz es importante. Me resisto a no citar un texto de Santo Tomás al respecto, en un comentario al Salmo 18: "El modo de hablar es triple: alto, humilde y mediocre. Hablar alto conviene al que persuade, el segundo modo (humilde) conviene al que enseña, el tercero (mediocre) al que deleita"32.

Para terminar, un bello texto de Innerarity que dice:

Al principio era la palabra. Probablemente las cosas dejen de ser así al final, cuando reine el silencio de la desesperación o la mirada gozosa. Tras la exposición universal no quedará nada por decir, porque el disimulo será imposible, si no hay extrañeza y opacidad que perdure. Pero en el mientras tanto también es la palabra; mejor dicho: las palabras ${ }^{33}$.

Mientras las palabras de los filósofos continúen preguntando, algo de lo humano segui- rá ahí, sin importar que nuestros cuerpos ya no sean lo que, hasta ahora, hemos conocido y aceptado como el destino biológico de la especie $^{34}$.

Quiero terminar con unos renglones del Canto general de Neruda, y luego la palabra escrita de unas pocas citas, que no hemos leído completas, a manera de recapitulación.

Sube a nacer conmigo, hermano.

Yo vengo a hablar por vuestra boca muerta.

A través de la tierra juntad todos los silenciosos labios derramados y desde el fondo habladme toda esta larga noche.

Dadme el silencio, el agua, la esperanza.

Acudid a mis venas y a mi boca.

Hablad por mis palabras y mi sangre $^{35}$.

\footnotetext{
Santo Tomás de Aquino, In Psalmo 18, citado en Beuchot , "Filosofía ...”, 168.

Innerarity, "La filosofía ...", 38.

Mejía, De clones ..., 40.

Pablo Neruda, Canto general (Ed. Orbis) 36.
} 